\title{
Bullet to the femoral head
}

This article was published in the following Dove Press journal:

Open Access Surgery

18 January 2016

Number of times this article has been viewed

\section{Krishna Akella \\ Nupur Murthy \\ Phoenix Bell \\ Akella Chendrasekhar}

Department of Surgery, Trauma

Section, Richmond University Medical

Center, Staten Island, NY, USA
Correspondence: Akella Chendrasekhar Department of Surgery, Richmond University Medical Center,

355 Bard Avenue, Staten Island, NY 10310, USA

Email achendra@aol.com
Abstract: A bullet being lodged in the femoral head is a unique trauma situation, which can be managed either operatively or non-operatively. We present two different scenarios of a bullet being lodged in the femoral head with a discussion of both operative and non-operative management as well as diagnostic considerations.

Keywords: penetrating, trauma, extremity

\section{Introduction}

A gunshot injury to an extremity is a common occurrence, with management being either operative or nonoperative, depending on the bullets' location and patient presentation. ${ }^{1}$ Possible complications include avascular necrosis, posttraumatic arthritis, infection, compartment syndrome, lead poisoning, fracture, and shock. We report on two unusual cases of gunshot wounds presenting with a bullet lodged in the femoral head. As this was a retrospective study looking at two patients where no patient identifiers were used, our institutional review board and our risk manager felt no consent was required from the patients nor was ethical approval required.

\section{Case I}

Our first patient was a 26-year-old male, with no significant past medical history, who was brought to the emergency room with multiple gunshot wounds to the elbow and hip. Plain radiographs and a computed tomography (CT) scan found a bullet lodged in the right femoral head (Figure 1) as well as a through-and-through injury to the upper extremity without any bone injury or residual deficit. He was then given Cefazolin and transferred to the intensive care unit. Orthopedic assessment was obtained. The patient appeared stable and no subsequent orthopedic operative management was deemed to be necessary. Physical therapy was initiated with full weight bearing on the injured extremity. The patient was able to tolerate this management and was discharged home after several days in the hospital.

\section{Case 2}

Our second patient was a 26-year-old male, with no past medical history, who was hospitalized due to a gunshot wound to the right buttock and abdomen. Subsequent imaging with CT found a bullet located in the right femoral head in addition to a fracture of the acetabulum (Figure 2). The patient was also noted to have a colonic perforation, secondary to a second gunshot wound to the abdomen, requiring a resection 


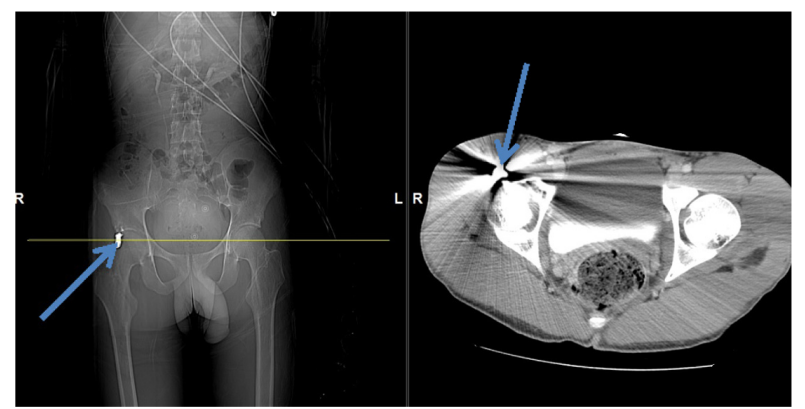

Figure I Computed tomography scan of patient (case I) with femoral head gunshot wound.

Note: Arrows point to the bullet lodged in the femoral head.

and end colostomy. To decrease the patients' pain and regain functional movement of the hip, surgical removal of the bullet fragment was deemed necessary. This procedure is technically challenging, as gaining access to the bullet requires joint dislocation and relocation following removal of the bullet. A standard posterolateral approach was used in order to access the hip joint and the femoral head. A trochanteric fragment osteotomy was also performed followed by a z-capsulotomy. The hip was dislocated anteriorly and the bullet fragment was removed. After the completion of the procedure, the patient was started on physical therapy with weight bearing as tolerated and was subsequently discharged home.

\section{Discussion}

Gunshot wounds to the extremity are a common occurrence. ${ }^{1}$ The most common firearm injury occurring in the civilian population is low-velocity, due to handguns. Greater kinetic energy transference, increased risk of compartment syndrome as well as greater extent of wound contamination are contributing factors as to why shotgun and high velocity wounds are more likely to cause devastating injury. ${ }^{2,3}$

Clinical presentation of extremity gunshot wounds is highly variable depending on the site of involvement and the extent of the damage. Critical factors of such an injury to consider include nerve and vascular damage, compartment
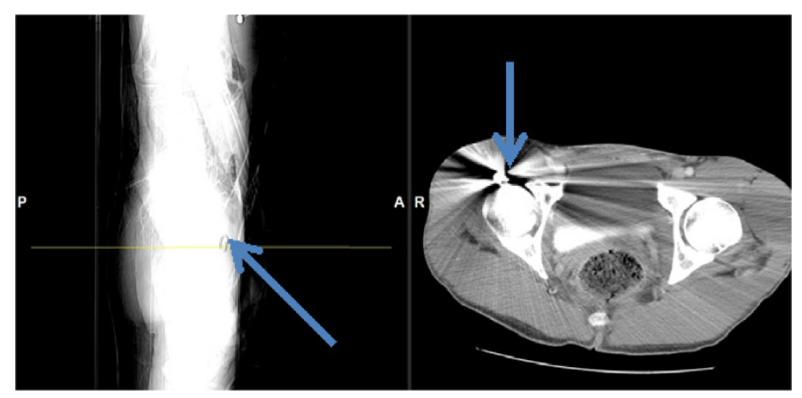

Figure 2 Computed tomography scan of patient (case 2) with femoral head gunshot wound.

Note: Arrows point to the bullet lodged in the femoral head. syndrome, fractures, and weapon type. Soft tissue is the predominant type of tissue injury in gunshot wounds. Neural and vascular injuries are primary determinants of both mortality and long-term outcomes in these patients. ${ }^{4-6}$

Extremity vascular injury and subsequent hemorrhage can induce hemodynamic instability and impact extremity viability. Fascial layer separation plays a central role in the pattern of injury due to the kinetic energy transfer involved in the immediate occurrence of the distal injury and late development of compartment syndrome. ${ }^{7}$ Penetrating lower extremity traumas most often damage the superficial femoral artery, followed by the popliteal artery, and the common femoral artery. Penetrating trauma resulting in amputation is most frequently associated with popliteal artery injury. ${ }^{8}$ Peripheral nerve injury due to trauma accounts for $2 \%-3 \%$ of traumatic injury. More commonly, these are associated with concomitant vascular injury. ${ }^{8-10}$

Lower extremity gunshots have the greatest fracture rate - primarily occurring in the femur $(22 \%-49 \%)$ and tibia $(11 \%-14 \%) .{ }^{11}$ Injury in these fractures can be due to the bullet itself or secondary to bone fragments damaging tissue and neurovascular supply. ${ }^{12,13}$ Severe femoral fractures and medial thigh wounds carry a significantly increased risk for vascular injury and massive hemorrhage. Tibial trauma is most commonly associated with the development of lower extremity compartment syndrome. Over $60 \%$ of penetrating lower extremity trauma patients who develop compartment syndrome have associated tibial fractures. ${ }^{14}$

The gold standard diagnostic modality to assess the degree of vascular injury is angiography. With a sensitivity of $99 \%-100 \%$ and specificity of $87 \%-100 \%$, CT angiography (CTA) has replaced conventional angiography in most cases. ${ }^{15-17}$ While duplex ultrasound is a diagnostic alternative with similar sensitivity and specificity, studies have often found diagnostic accuracy to be user dependent. ${ }^{14,18}$

Timing of presentation after injury plays a critical role in a patients' outcome. A delay $>6-8$ hours has been found to be associated with significantly higher complication rates. ${ }^{7}$ If there is concern for vascular injury, admission with serial examinations in addition to CTA is a commonly accepted management strategy. Post-gunshot nerve injury is very difficult to assess within the acute period. Seventy percent of patients with documented peripheral nerve injury make a complete recovery. ${ }^{10}$ Frequent neurologic status assessments are important in the management of gunshot wound patients as an indicator of the development of compartment syndrome.

Management of post-gunshot fractures generally requires reduction with anatomic realignment, followed by soft tissue care, and splinting. Obvious contamination, large size, and 
joint involvement are indicatiors for the use of intravenous antibiotics. Definitive management of joint and bone injury is often surgical. Indication for operative management of bullets in joints is dependent on the degree of joint involvement and the ability to bear weight and perform normal function. As was the case in one of our patients, one was managed nonoperatively. Both had successful outcomes. Soft tissue injury management is dependent on wound size. Small wounds are isolated to the skin, subcutaneous tissue, and muscle and are managed with a combination of irrigation, debridement, and antibiotics in the outpatient setting. Outpatient management of these cases has been found to reduce overall complication rate., ${ }^{219}$ Wounds that are large, deep, have cosmetic implication, or older than 8 hours require operative management and hospital admission. ${ }^{20}$

One other issue is the lodging of bullets or pellets in relatively inaccessible parts of the body. The management of the bullet can be either operative or nonoperative. In general, if the bullet is lodged in soft tissue away from vital structures, the nonoperative approach is preferred. However if the bullet is in a joint space, the bullet is not physiologically inert and should be removed. ${ }^{21}$

\section{Conclusion}

Extremity gunshot wounds are complex with a wide variety of clinical presentations. Joint involvement in the context of extremity gunshot wounds is a particularly rare phenomenon. Both of our cases were unusual in this respect; both had different management strategies and equivalent outcomes. Injury in gunshot wounds can occur at different levels, including soft tissue, neurovascular supply, and bone. Diagnosis of vascular injury involves the use of CTA or duplex ultrasonography. Management depends on the type of injury. Fracture management involves reduction, soft tissue care, and splinting. Soft tissue care involves the use of irrigation, debridement, and antibiotics. We have shown two different and equally acceptable approaches to the management of a bullet lodged in the femoral head.

\section{Disclosure}

The authors report no conflicts of interest in this work.

\section{References}

1. Dougherty PJ, Najibi S, Silverton C, Vaidya R. Gunshot wounds: epidemiology, wound ballistics, and soft-tissue treatment. Instr Course Lect. 2009;58:131-139.
2. Byrne A, Curran P. Necessity breeds invention: a study of outpatient management of low-velocity gunshot wounds. Emerg Med J. 2006;23(5): 376-378.

3. Oakes R, Urban A, Levy PD. The mangled extremity. $J$ Emerg Med. 2008;35(4):437-444.

4. Gotsch KE, Amnest JL, Mercy JA, et al. Surveillance for fatal and nonfatal firearm-related injuries - United States, 1993-1998. MMWR. 2001;50(S S02):1-32.

5. Hollerman JJ, Facker ML, Coldwell DM, Ben-Menachem Y. Gunshot wounds: 1. Bullets, ballistics, and mechanisms of injury. AJR Am J of Roentgenol. 1990;155(4):685-690.

6. Watters J, Anglen JO, Mullis BH. The role of débridement in low-velocity civilian gunshot injuries resulting in pelvis fractures: a retrospective review of acute infection and inpatient mortality. $J$ Orthop Trauma. 2011;25(3):150-155.

7. Ragsdale BD, Josselson A. Experimental gunshot fractures. J Trauma. 1988;28(1 Supp):S109-S115.

8. McSwain NE. Ballistics. In: The Textbook of Penetrating Trauma. Ivatury RR, Cayte CG, editors. Baltimore: Williams \& Wilkins, 1996:108

9. Noble J, Munro CA, Prasad VS, Midha R. Analysis of upper and lower extremity peripheral nerve injuries in a population of patients with multiple injuries. J Trauma. 1988;45(1):116-122.

10. Yegiyants S, Dayicioglu D, Kardashian G, Panthaki ZJ. Traumatic peripheral nerve injury: a wartime review. J Craniofacial Surg. 2010;21(4):998-1001.

11. Bartlett C. Clinical update: gunshot wound ballistics. Clin Orthop Relat Res. 2003;(408):28-56.

12. Frykberg ER, Dennis JW, Bishop K, Laneve L, Alexander RH. The reliability of physical examination in the evaluation of penetrating extremity trauma for vascular injury: results at one year. $J$ Trauma. 1991;31(4):502-511.

13. Moed BR, Fakhouri AJ. Compartment syndrome after low-velocity gunshot wounds to the forearm. J Orthop Trauma. 1991;5(2): 134-137.

14. Gonzalez RP, Scott W, Wright A, Phelan HA, Rodning CB. Anatomic location of penetrating lower-extremity trauma predicts compartment syndrome development. Am J Surgery. 2009;197(3):371-375.

15. Inaba K, Potzman J, Menura F, et al. Multi-slice CT angiography for arterial evaluation in the injured lower extremity. $J$ Trauma. 2006;60(3):502-507.

16. Peng PD, Spain DA, Tataria M, Hellinger JC, Rubin GD, Brundage SI. CT angiography effectively evaluates extremity vascular trauma. $\mathrm{Am}$ Surg. 2008;74(2):103-107.

17. Rieger M, Mallouhi A, Tauscher T, Lutz M, Jaschke WR. Traumatic arterial injuries of the extremities: initial evaluation with MDCT angiography. AJR Am J Roentgenol. 2006;186(3):656-664.

18. Long WT, Brien EW, Boucree JB Jr, Filler B, Stark HH, Dorr LD. Management of civilian gunshot injuries to the hip. Orthop Clin North Am. 1995;26(1):123-131.

19. Ordog GJ, Sheppard GF, Wasserberger JS, Balasubramanium S, Shoemaker WC. Infection in minor gunshot wounds. J Trauma. 1993;34(3):358-365.

20. Burg A, Nachum G, Salai M, et al. Treating civilian gunshot wounds to the extremities in a level 1 trauma center: our experience and recommendations. Isr Med Assoc J. 2009;11(9):546-551.

21. Sclafani SJ, Vuletin JC, Twersky J. Lead arthropathy: arthritis caused by retained intra-articular bullets. Radiology. 1985;156(2):299-302. 
Open Access Surgery

Dovepress

\section{Publish your work in this journal}

Open Access Surgery is an international, peer-reviewed, open access journal that focuses on all aspects of surgical procedures and interventions. Patient care around the peri-operative period and patient outcomes post surgery are key topics. All grades of surgery from minor cosmetic interventions to major surgical procedures are covered. Novel techniques and prostheses that optimize outcomes constitute major areas of interest. The manuscript management system is completely online and includes a very quick and fair peer-review system. Visit http://www.dovepress.com/ testimonials.php to read real quotes from published authors. 